\title{
Youth onset Type 2 diabetes and elevated cardiovascular disease risk- a registry based case-control study from India
}

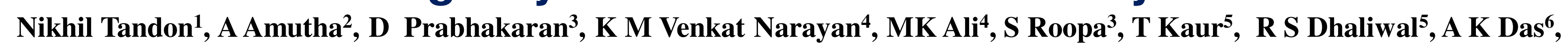
C S Yajnik ${ }^{7}$, V Mohan ${ }^{2}$, PA Praveen ${ }^{1}$

${ }^{1}$ All India Institute of Medical Sciences, New Delhi, India, ${ }^{2}$ Madras Diabetes Research Foundation, Chennai, India, ${ }^{3}$ Public Health Foundation of India, Gurugram, India, ${ }^{4}$ Emory Global Diabetes Research Center, Rollins School of Public Health, Emory University, Atlanta, USA, 5 Indian Council of Medical Research, New Delhi, India, ${ }^{6}$ Pondicherry Institute of Medical Sciences, India, ${ }^{7}$ King Edward Memorial Hospital and Research Centre, Pune, India.

\section{Background}

Cardiovascular diseases (CVD) are one of the leading causes of mortality among youth onset diabetes. There are limited data on the CVD risk factor profile of youth with type 2 diabetes (age at diagnosis $\leq 25$ years).

\section{Methods}

* A case-control study was conducted to compare the CVD risk factor profile of youth onset diabetes patients (aged 20 years and above) with their age, gender and geographic location matched controls without diabetes.

* People with diabetes were recruited from the Chennai reporting centre of the Registry of people with diabetes in India with young age at the onset (YDR). The control population was selected from the CARRS (Cardio metabolic Risk Reduction in South Asia) cohort from Chennai, India

* Individuals with fasting plasma glucose $<126 \mathrm{mg} / \mathrm{dl}$ were recruited as controls.

* Both YDR and CARRS used similar standard methodologies to quantify the behavioural, anthropometric and biochemical risk factors of CVD.

\section{Objectives}

* To estimate the prevalence of traditional cardiovascular risk factors among youth onset type 2 diabetes and to compare with the general population without diabetes.

\section{Results}

* Current smoking and alcohol use was significantly higher in people without diabetes.

* Patients with type 2 diabetes consumed more fruits and vegetables but had low level of physical activity compared to control subjects.

* Youth onset type 2 diabetes patients had high prevalence of both generalized and abdominal obesity and hypertension (Table-1).

* Despite low mean levels of lipid parameters, the prevalence of dyslipidaemia, which took in to account medication use, was significantly higher among patients with youth onset type 2 diabetes compared to controls (Table-1).

* Overall, patients with type 2 diabetes had a less favourable CVD risk profile compared to control population (Figure-1).

* The prevalence of four or more CVD risk factors in women with type 2 diabetes was significantly higher than that of men $(17.9 \%$ vs $7.0 \%)$

\begin{tabular}{|c|c|c|c|c|}
\hline & Type 2 diabetes & Controls & Adjusted Odds ratio & Adjusted Odds ratio \\
\hline Body Mass Index (BMI) & $n=201$ & $\mathrm{n}=342$ & & - \\
\hline Underweight $\left(B M I<18 \mathrm{Kg} / \mathrm{m}^{2}\right)$ & $4(1.9)$ & $26(7.6)$ & $0.4(0.1,1.3)^{*}$ & - \\
\hline Overweight $\left(B M I \geq 25 \mathrm{Kg} / \mathrm{m}^{2} \&<30 \mathrm{Kg} / \mathrm{m}^{2}\right)$ & $98(48.8)$ & $131(38.3)$ & $1.8(1.1,2.9)^{*}$ & - \\
\hline Obese $\left(B M I \geq 30 \mathrm{Kg} / \mathrm{m}^{2}\right)$ & $43(21.4)$ & $41(12.0)$ & $3.3(1.7,6.1)^{*}$ & \\
\hline Waist circumference (WC)- IDF criteria & $\mathrm{n}=201$ & $\mathrm{n}=371$ & & \\
\hline$W C>90 \mathrm{~cm}$ (men) \& WC>80 cm (women) & $130(64.7)$ & $149(40.1)$ & $3.0(2.0,4.7)^{*}$ & - \\
\hline Waist circumference (WC)- NCEP criteria & $\mathrm{n}=201$ & $\mathrm{n}=371$ & & - \\
\hline$W C>102 \mathrm{~cm}$ (men) \& WC>88cm (women) & $67(33.3)$ & $48(12.9)$ & $4.9(2.9,8.4)^{*}$ & - \\
\hline Abdominal obesity & $\mathrm{n}=181$ & $\mathrm{n}=371$ & & \\
\hline Waist to hip ratio $>0.90$ for men $>0.85$ for women & $137(75.7)$ & $183(49.2)$ & $4.2(2.6,6.8)^{*}$ & - \\
\hline Blood pressure & $\mathrm{n}=201$ & $\mathrm{n}=373$ & & \\
\hline $\begin{array}{l}\text { Pre hypertension (SBP 120-139 mmHg and/or DBP 80-89 } \\
\mathrm{mmHg} \text { ) }\end{array}$ & $77(38.3)$ & $115(30.8)$ & $5.9(3.2,10.9)^{\$}$ & $2.6(0.9,7.8)^{\#}$ \\
\hline $\begin{array}{l}\text { Hypertension (SBP } \geq 140 \mathrm{~mm} \mathrm{Hg} \text { and/or } D B P \geq 90 \mathrm{mmHg} \text { or } \\
\text { on medication) }\end{array}$ & $96(47.7)$ & $52(13.9)$ & $15.5(7.9,30.2)^{\$}$ & $7.0(2.1,22.8)^{\#}$ \\
\hline Low Density Lipoprotein (LDL) cholesterol & $\mathrm{n}=201$ & $\mathrm{n}=402$ & & \\
\hline$L D L \geq 130 \mathrm{mg} / \mathrm{dl}$ & $23(11.4)$ & $88(22.4)$ & $0.4(0.2,0.8)^{\$}$ & $0.1(0.02,0.6)^{\#}$ \\
\hline Dyslipidaemia $^{\wedge}$ & $\mathrm{n}=201$ & $\mathrm{n}=402$ & & \\
\hline Yes & $185(92.0)$ & $318(79.1)$ & $3.3(1.6,6.7)^{\$}$ & $5.6(1.3,24.7)^{\#}$ \\
\hline
\end{tabular}

Figure-1: Clustering of Cardiovascular Disease risk Factors

- Type 2 diabetes $(\mathrm{N}=181) \quad$ Controls $(\mathrm{N}=332)$

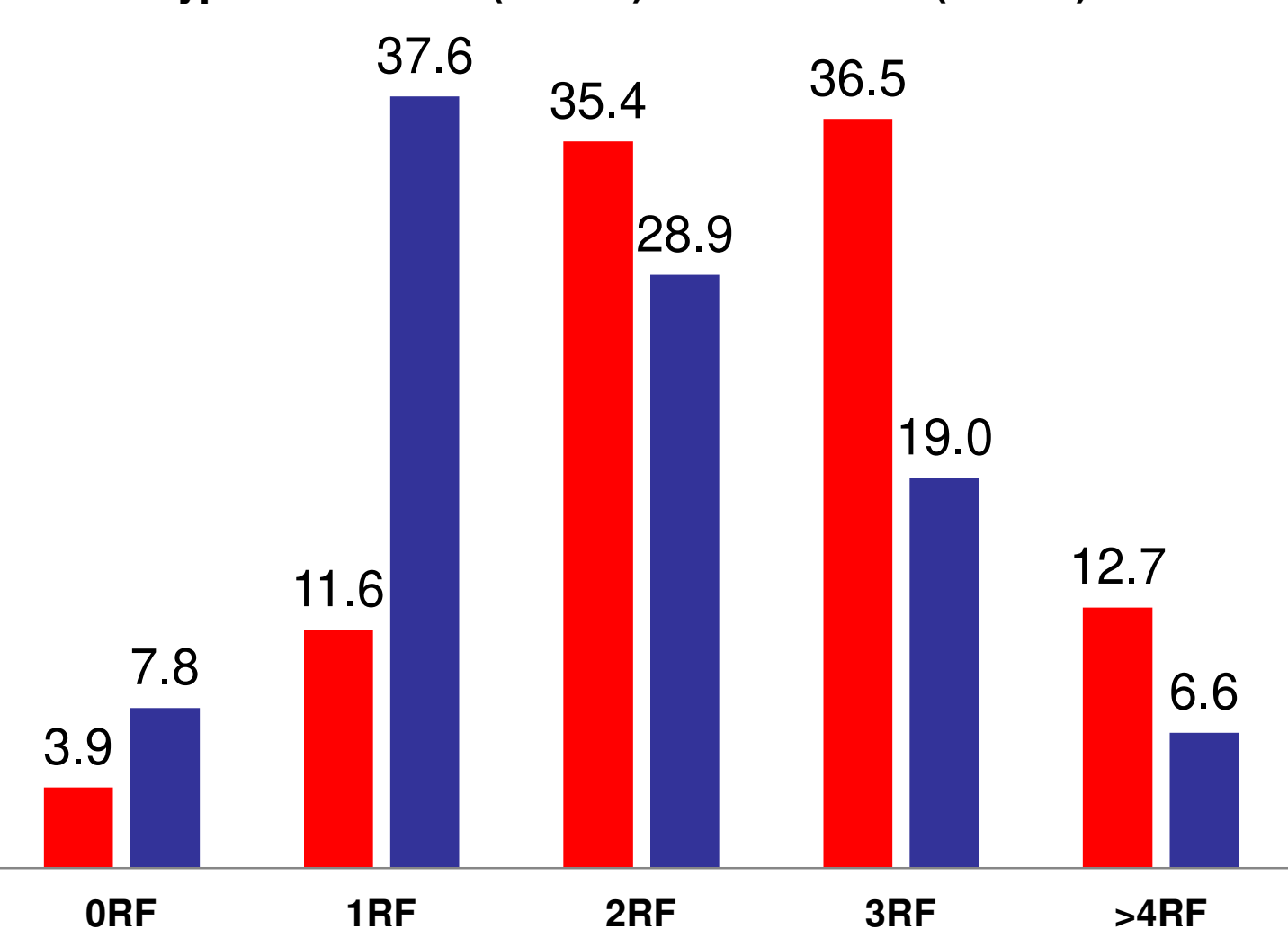

\section{Conclusions}

* This study found that the patients with youth onset diabetes had an adverse cardiovascular profile compared to the control population

* The high clustering of CVD risk factors in type 2 diabetes call for urgent secondary prevention strategies to curtail the burden of CVD in this young productive population
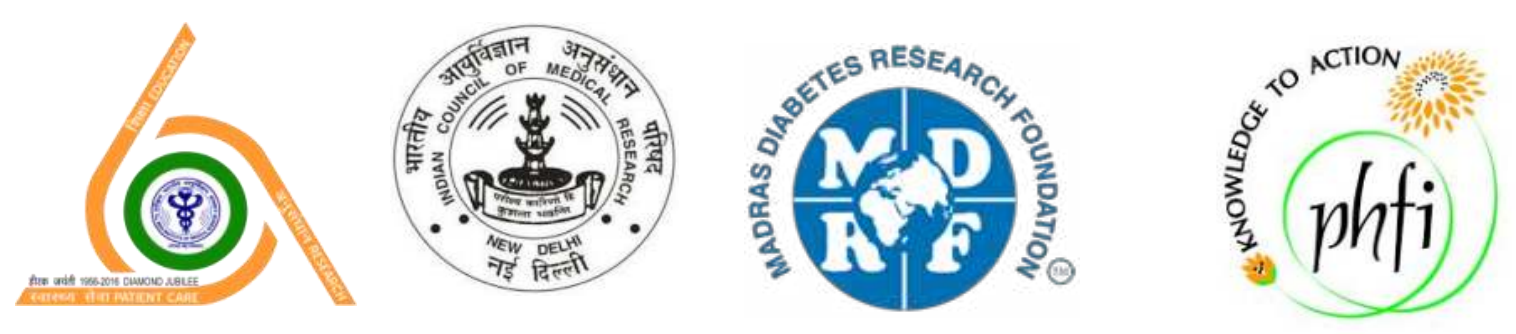

> The YDR registry was funded by the Indian Council of Medical research, New Delhi, India; The CARRS cohort was funded by NHLBI, National Institutes of Health, USA 